\title{
MECHANICAL PERFORMANCE OF RECYCLED AGGREGATE SELF-CONSOLIDATING CONCRETE COLUMN
}

\author{
Feng YU, Chaochao FENG, Shilong WANG*, Wei HUANG, Yuan FANG, Shuangshuang BU \\ Department of Civil Engineering and Architecture, Anhui University of Technology, Ma'anshan, PR China
}

Received 14 June 2020; accepted 27 November 2020

\begin{abstract}
The utilization of recycled concrete aggregate (RCA) can reduce the environmental impact and decreases the cost of concrete. In this study, a comprehensive assessment of self-consolidating concrete (SCC) using RCA as partial or total replacement of coarse aggregate was conducted. Recycled concrete aggregate self-consolidating concrete (RCA-SCC) mixtures with varied water-to-cement (W/C) ratios (0.28-0.46), sand-to-aggregate (S/A) ratios (48-52\%), fly ash (FA) contents $(20-40 \%)$, RCA replacement ratios (0-100\%), and water reducer contents $(0-1.5 \%)$ were designed and tested. 5 groups of the RCA-SCC columns with different W/C and replacement ratios of RCA were also investigated. The slump flow, the J-ring flow and the cubic compressive strength, and the compressive behaviors of the RCA-SCC columns were studied. Results indicated that W/C ratio was the dominant parameter in RCA-SCC mixture, and the failure modes of the RCA-SCC columns were similar to those of the conventional concrete columns. Based on the experimental results, the mechanical performance of RCA-SCC columns was evaluated quantitatively, and a stress-strain relation model for predicting the axial compressive behavior of RCA-SCC column was proposed. This study will provide a reference for the engineering application of the environment-friendly SCC using RCA that are derived from tested or returned concretes with better performance.
\end{abstract}

Keywords: recycled aggregate, self-consolidating concrete, compressive strength, peak stress, stress-strain relationship.

\section{Introduction}

With the promotion of urbanization and the forthcoming end of life of the numerous old buildings, voluminous construction and demolition waste (C\&DW) are likely to be produced in China (Wu et al., 2016b), which has posed a serious threat to environmental and economic benefits. Therefore, recycling demolished concrete into fresh concrete seems to be a sustainable and economical approach to solve such difficulties raised in construction industry. As a typical product of construction waste utilization, recycled concrete aggregate (RCA) has attracted considerable research interests due to the environment-friendly property they possess to utilize demolished concrete as partial or total substitution for natural aggregates (Huang et al., 2015; Mi et al., 2020).

Compared with conventional concrete, RCA exhibits more complicated meso-structures since the interfacial transition zones (ITZs) exist not only between recycled coarse aggregate and new mortar matrix but also between recycled coarse aggregate and adhered mortar (Tam et al., 2005). Observation of scanning electron microscopy on
RCA indicates that a large of minute pores and cracks were assembled within ITZ between the coarse RCA and mortar matrix, which might have a critical effect on the strength of RCA (Etxeberria et al., 2006). It was reported that the microcracks could contribute to the formation of the weakest links in ITZ and the high stress concentration at the crack tips (González-Fonteboa \& Martínez-Abella, 2008). Thus, the propagation of these microcracks was initiated in ITZs during the failure process of RCA ( $\mathrm{Li}$ et al., 2017). Besides, the quality (high compressive strength, flexural and split tensile strengths) of RCA is also determined by several other factors, such as RCA content (Kou et al., 2007; Etxeberria et al., 2007; Xiao et al., 2012), the quality of original concrete (Assaad et al., 2020; Thomas et al., 2018) and the presence of contaminants (Noguchi et al., 2015). Nowadays, the relatively poor quality of recycled aggregate concrete is still a critical issue that largely restricts its wide application in civil and industrial construction (Olorunsogo \& Padayachee, 2002; V. Tam $\&$ C. Tam, 2007). Therefore, a deep understanding of the

*Corresponding author. E-mail: wshilong2012@163.com

Copyright () 2021 The Author(s). Published by Vilnius Gediminas Technical University

This is an Open Access article distributed under the terms of the Creative Commons Attribution License (http://creativecommons.org/licenses/by/4.0/), which permits unrestricted use, distribution, and reproduction in any medium, provided the original author and source are credited. 
mechanical properties of RCA is necessary to further improve the performance of RCA and to promote the feasibility of using RCA involved in the construction industry.

Self-consolidating concrete (SCC), which was first developed by Ozawa (1989), is an innovative concrete with high flowability and non-segregating characteristics. SCC has been one of the most significant developments in concrete technology over past few decades. SCC can be self-compacted into every corner of a formwork even in the existence of congested reinforcement (Okamura \& Ouchi, 2003), purely under its own weight without vibration, which could reduce the substantial labour cost and construction time. To achieve good performance of SCC in some difficult construction conditions, such as concrete structures with congested zones, extensive researches on rheological properties of the fresh SCC were carried out. A detailed performance of the practical SCC at fresh state was evaluated by performing slump test, $\mathrm{V}$-funnel flow time test and sieve stability tests (Omrane et al., 2017). It was observed that the V-funnel flow time of SCC increased with the increase of natural pozzolan content. However, to maintain high flowability and consistency of mixture, SCC requires large amount of cement and admixtures, which results in a relatively high cost as compared with other available concretes. Accordingly, the approach to prepare a cost-effective SCC with desirable fresh properties is necessary to meet the demand of such concrete in construction industry. Nowadays, a beneficial awareness is gradually advocated that the replacement of natural aggregate with RCA which is mainly produced from demolished concrete of C\&DW is available. Kou and Poon (2009) studied the fresh and hardened properties of SCC in which the river sand was replaced by fine RCA. The results indicated that the slump flow and blocking ratio of recycled concrete aggregate self-consolidating concrete (RCA-SCC) mixtures raised with increase of fine RCA content while the compressive and tensile strengths had reverse trend. Matar and Assaad (2019) further introduced polypropylene fibers to RCA-SCC, and the coupled effects of RCA and polypropylene fibers on workability of RCA-SCC were investigated. Results indicated that the existence of polypropylene fibers could attenuate the passing ability but increase the stability of RCA-SCC. Actually, the acceptable properties of SCC would be held even the replacement ratio of RCA was up 50\% in SCC (Safiuddin et al., 2011; Khodair \& Bommareddy, 2017; Señas et al., 2016). Naturally, using locally available RCA to develop SCC technology is always an encouraged and welcome practice to make SCC much economical and sustainable (Ahmad et al., 2014).

Indeed, the effects of RCA and FA on the mechanical properties of RCA-SCC have been investigated in recent years. Generally, the compressive strength and the workability of RCA-SCC decreased with the increase of RCA replacement ratio due to the angularity and surface roughness of RCA (Señas et al., 2016), and an appropriate FA content would contribute to improve the working performance and strength of RCA-SCC (Matos et al., 2019; Yao et al., 2020). Besides, the sand-to-aggregate ratio was also an important factor influencing the compressive strength and the operating performance (Zhang et al., 2008). Moreover, the formwork pressure induced by SCC was quantitatively evaluated by considering the RCA and the presence of reinforcing bars (Assaad \& Matar, 2018). Yet, the existing investigations on RCA-SCC were mainly focused on the fresh and harden properties of materials, whereas the mechanical performance of RCA-SCC involved members and structures was rarely reported, which restricted the deep understanding and the widespread application of RCA structures in civil engineering.

The purpose of this study was to optimize the mix design by accounting for the influence of multiple factors (such as water-to-cement ratio, RCA replacement ratio, sand-to-aggregate ratio, FA content and water reducer content) to provide RCA-SCC with better performance. Based on the experimental results and the available experimental data in published literature, some regression models, including peak stress, peak strain, elastic modulus elasticity, Poisson's ratio and stress-strain relationship model, were developed to predict the mechanical performance of RCA-SCC column. The determined mechanical properties of RCA-SCC columns will also be a useful benchmark for evaluating the accuracy of numerical methods or the developed theoretical model.

\section{Details of experiments}

\subsection{Materials}

The ordinary P. O42.5 cement was used as the cementitious material in the RCA-SCC mixtures and FA was adopted to replace cement partly to improve the workability of concrete mixture. High-range water-reducing admixtures (HRWRA) were also added to the concrete mixtures. The coarse RCA was recycled from tested concrete cube specimens that were sourced from a local engineering quality inspection Co., Ltd. To achieve a relatively uniform strength of RCA, the waste concrete cubes with strength grade ranging within C30 C35 were selected to prepare coarse RCA. The process to obtain RCA from demolished concrete was a manufacturing technology by properly combining the crushing equipment, transfer equipment and sieving equipment. Pre-sorting operation on the collected concrete cube specimens was necessary to make the same basic characteristic of the RCA due to the wide variety of the demolished concrete specimens. Then, the crushed concrete wastes were conveyed to sieving machine to control the particle sizes of the RCA. The detailed process of manufacturing RCA from discarded concrete fragments was schematized in Figure 1.

Finally, the RCA grains were washed by water pressure to remove any detached mortar and impurity from the aggregates to guarantee the good adhesion between RCA and cement mortar. Compared with natural coarse aggregates, the recycled aggregates exhibit relatively higher surface roughness and porosity. Moreover, the acicular (needle-shaped) RCA was eliminated since such kinds of 


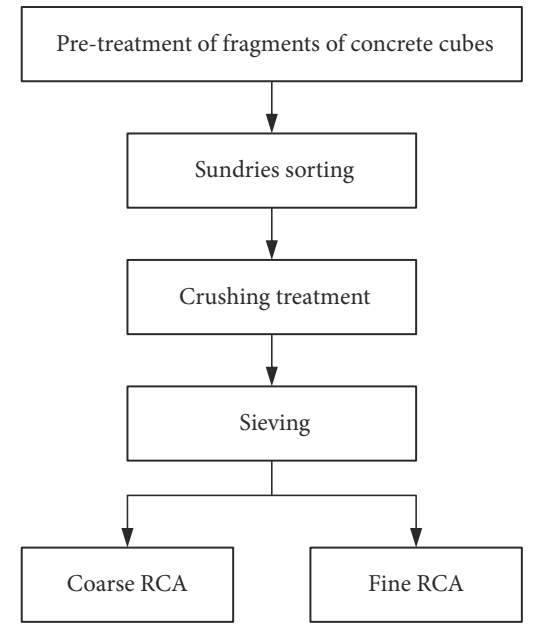

Figure 1. The basic process flowchart of manufacturing RCA

aggregates might affect the fluidity of self-consolidating concrete mixture. Then, RCA with three different particle sizes within ranges of 5-15 mm, 15-25 mm and 25-31.5 mm were obtained, whereas the fine RCA with particle size below $5 \mathrm{~mm}$ were not used. The continuous graded RCA with particle sizes from 5 to $31.5 \mathrm{~mm}$, which complied with the Chinese Standard GB/T 25177-2010 (China Academy of Building Research, 2010), was used as coarse aggregate in RCA-SCC mixtures. The gradation of the RCA is presented in Table 1.

Table 1 . The gradation of the adopted recycled concrete aggregate

\begin{tabular}{|c|c|c|c|c|c|}
\hline Sieve size $(\mathrm{mm})$ & 4.75 & 9.50 & 16.0 & 19.0 & 26.5 \\
\hline Cumulative sieve residue (\%) & 100 & 93.8 & 67 & 32.2 & 20.4 \\
\hline
\end{tabular}

The natural river sand with an apparent density of $2625 \mathrm{~kg} / \mathrm{m}^{3}$ was used as fine aggregate, whereas the continuous graded gravel with a grain size of $5-31.5 \mathrm{~mm}$ was adopted as natural coarse aggregate. The apparent densities of the coarse RCA and the natural coarse aggregate were $2680 \mathrm{~kg} / \mathrm{m}^{3}$ and $2595 \mathrm{~kg} / \mathrm{m}^{3}$, respectively. The water absorption of the adopted coarse RCA and the nature coarse aggregate were $4.6 \%$ and $0.85 \%$, respectively, whereas the crushing indexes of coarse RCA and nature coarse aggregate were $15.8 \%$ and $7.6 \%$, respectively. The large water absorption and crushing index of coarse RCA were mainly resulted from the adhered old mortar content.

\subsection{Mixture proportions}

The influence of W/C ratio, sand-to-aggregate (S/A) ratio, FA content, HRWRA and RCA replacement ratio on the properties of RCA-SCC mixtures was comprehensively investigated in the present study. All of the five considered parameters were prepared with four different levels. The complete mix design of the RCA-SCC is listed in Table 2.

Due to the high water absorption of RCA, the presoaked treatment was operated to make RCA being in saturated surface dry condition, which could lessen the influence on the effective W/C ratio. The amount of additional water for soaking RCA was positively correlated with the amount of the adopted RCA and water absorption. The $\mathrm{W} / \mathrm{C}$ ratios were selected as $0.28,0.32,0.38$ and 0.46 , respectively. RCA replacement ratios of $0 \%, 30 \%$, $60 \%$ and $100 \%$ were considered, and the contents of the HRWRA of $0 \%, 0.5 \%, 1 \%$ and $1.5 \%$ were adopted. For each W/C ratio, the orthogonal combination of the corresponding parameters led to four mixture proportions of RCA-SCC. Hence, totally 16 different mix designs of

Table 2. Detailed mix design of RCA-SCC mixtures

\begin{tabular}{|c|c|c|c|c|c|c|c|c|c|c|c|}
\hline \multirow{2}{*}{ No. } & \multirow{2}{*}{$\begin{array}{l}\mathrm{W} / \mathrm{C} \\
\text { ratio }\end{array}$} & \multirow{2}{*}{$\begin{array}{l}\text { Water } \\
(\mathrm{kg})\end{array}$} & \multirow{2}{*}{$\begin{array}{l}\text { Additional } \\
\text { water }(\mathrm{kg})\end{array}$} & \multicolumn{2}{|c|}{ River sand } & \multirow{2}{*}{$\begin{array}{l}\text { Cement } \\
(\mathrm{kg})\end{array}$} & \multirow{2}{*}{$\begin{array}{l}\text { FA } \\
(\mathrm{kg})\end{array}$} & \multicolumn{2}{|c|}{ HRWRA } & \multicolumn{2}{|c|}{ Recycled aggregate } \\
\hline & & & & $(\mathrm{kg})$ & (vol \%) & & & (kg) & (vol \%) & Weight (kg) & Percentage (\%) \\
\hline $\mathrm{Z1}$ & 0.28 & 164 & 0 & 736.2 & 48 & 477 & 113 & 0 & 0 & 0 & 0 \\
\hline $\mathrm{Z} 2$ & 0.28 & 164 & 11 & 797.5 & 50 & 449 & 137 & 2.93 & 0.5 & 240 & 30 \\
\hline $\mathrm{Z3}$ & 0.28 & 164 & 22 & 841.1 & 52 & 419 & 160 & 579 & 1 & 478 & 60 \\
\hline $\mathrm{Z} 4$ & 0.28 & 164 & 36.7 & 936.2 & 54 & 391 & 185 & 8.64 & 1.5 & 798 & 100 \\
\hline $\mathrm{Z5}$ & 0.32 & 176 & 11 & 936.2 & 54 & 395 & 151 & 0 & 0 & 240 & 30 \\
\hline Z6 & 0.32 & 176 & 0 & 841.1 & 52 & 366 & 173 & 2.695 & 0.5 & 0 & 0 \\
\hline $\mathrm{Z7}$ & 0.32 & 176 & 36.7 & 797.5 & 50 & 449 & 106 & 5.55 & 1 & 798 & 100 \\
\hline $\mathrm{Z8}$ & 0.32 & 176 & 22 & 736.2 & 48 & 421 & 128 & 8.235 & 1.5 & 478 & 60 \\
\hline Z9 & 0.38 & 193 & 22 & 797.5 & 50 & 335 & 158 & 0 & 0 & 478 & 60 \\
\hline $\mathrm{Z} 10$ & 0.38 & 193 & 36.7 & 736.2 & 48 & 361 & 138 & 2.495 & 0.5 & 798 & 100 \\
\hline Z11 & 0.38 & 193 & 0 & 936.2 & 54 & 386 & 117 & 5.03 & 1 & 0 & 0 \\
\hline $\mathrm{Z} 12$ & 0.38 & 193 & 11 & 841.1 & 52 & 409 & 97 & 7.59 & 1.5 & 240 & 30 \\
\hline $\mathrm{Z} 13$ & 0.46 & 210 & 36.7 & 841.1 & 52 & 349 & 106 & 0 & 0 & 798 & 100 \\
\hline Z14 & 0.46 & 210 & 22 & 936.2 & 54 & 372 & 88 & 2.3 & 0.5 & 478 & 60 \\
\hline $\mathrm{Z} 15$ & 0.46 & 210 & 11 & 736.2 & 48 & 305 & 144 & 4.49 & 1 & 240 & 30 \\
\hline Z16 & 0.46 & 210 & 0 & 797.5 & 50 & 326 & 125 & 6.765 & 1.5 & 0 & 0 \\
\hline
\end{tabular}


RCA-SCC mixtures with numbered Z1 to Z16 were obtained. The manufacturing process of RCA-SCC mixtures was conformed to the Chinese Standard GB/T 50080-2016 (China Academy of Building Research, 2016).

\subsection{Test procedure}

The fresh-state properties of RCA-SCC mixtures were evaluated by carrying out the slump flow test (diameter and T500) and the J-ring test (diameter and height). The determination of RCA-SCC properties was on the basis of technical specification for the application of JGJ/T 2832012 (China Academy of Building Research, 2012). For the slump flow test, a standard Abrams cone was tightly trampled on the experimental platform, and the cone was filled with RCA-SCC mixture without rodding. After two seconds, the cone was raised to 300 millimeters in height and the time, referred to as T500, was measured as the RCA-SCC mixture spreads to 500 millimeters diameter. A J-ring test setup consisted of a ring with reinforcing bar around the base and a slump cone. Before the test, the J-ring, cone and platform were firstly lubricated with water. The cone was inversely put on the platform and was concentric with the J-ring. Then, the cone was lifted quickly up to a height of 300 millimeters within two seconds, and the expansion diameter was determined to assess the separation resistance of the RCA-SCC mixture. Additionally, 16 groups of RCA-SCC cubes of $100 \times 100 \times 100 \mathrm{~mm}$ were manufactured to study the compressive strength of the hardened RCA-SCC mixtures and three duplicate specimens were prepared for each group to determine the curing age effect. The mold plates were removed 24 hours after casting the RCA-SCC cubes. Subsequently, the concrete specimens were cured to the corresponding ages of 7,14 and 28 days in a standard curing box.

Further, five groups of RCA-SCC cube columns of $150 \times 150 \times 550 \mathrm{~mm}$ at a time past the typical 7,14 and 28 days were manufactured. The mix design of five groups of RCA-SCC columns is listed in Table 3 in which the RCA-SCC columns with W/C ratios of $0.46,0.32$ and 0.28 corresponded to the mixtures of $\mathrm{Z} 15, \mathrm{Z} 5$ and $\mathrm{Z} 1$ respectively. Five groups of RCA-SCC columns were denoted as RCA-SCC-1, RCA-SCC-2, RCA-SCC-3, RCA-SCC-4 and RCA-SCC-5, respectively. Two duplicate specimens were prepared for each group, one for studying the stress-strain behavior and the other one for determining elastic modulus. The hydraulic universal material testing machine was adopted to examine the compressive behavior of RCA-
SCC columns subjected to axial load. The strain gauges were used to monitor and record the deformation of the column at concerned locations, as shown in Figure 2.

Before the test, the pre-load was adopted to ensure the load being exerted on the centerline of specimen exactly. Two different methods of the exerting load were applied to control the compression process of RCA-SCC columns. One method was the step loading method where each loading consisting of $1 / 10$ of the ultimate bearing capacity was applied for two minutes. When the failure behavior of specimen was almost initiated, the load was exerted by a slow continuous manner until the final failure of specimen. Another method to apply load followed the process that the reference load $F_{0}$ with $0.5 \mathrm{MPa}$ was exerted by holding for 60 seconds, and strains on the measuring points were recorded in the following 30 seconds. Then, the load was uniformly increased to a quarter of the compression strength of concrete specimen with a loading rate of $0.3 \mathrm{MPa} / \mathrm{s}$. Again, the read on the measuring points was recorded within 30 seconds after 60 seconds continuous loading. The scheme of the elasticity modulus load method is shown in Figure 3.

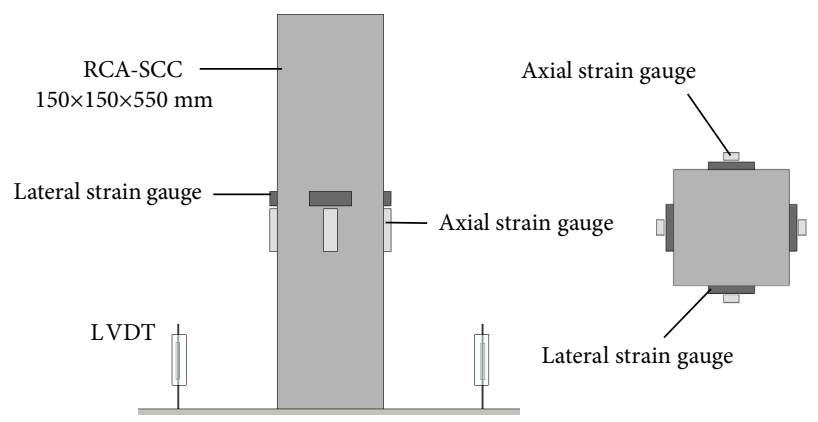

Figure 2. Arrangement of strain gauges and LVDT on RCA-SCC column

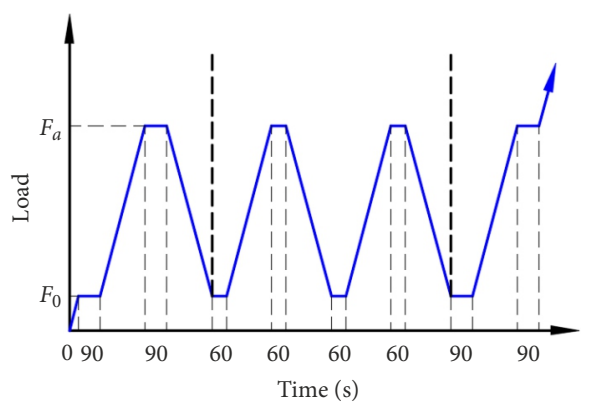

Figure 3 . The process of elasticity modulus load method

Table 3. Mix design of five groups of RCA-SCC columns

\begin{tabular}{|c|c|c|c|c|c|c|c|c|}
\hline \multirow{2}{*}{ No. } & \multirow{2}{*}{$\begin{array}{l}\mathrm{W} / \mathrm{C} \\
\text { ratio }\end{array}$} & \multirow{2}{*}{$\begin{array}{l}\text { water } \\
(\mathrm{L})\end{array}$} & \multirow{2}{*}{$\begin{array}{l}\text { Natural sand } \\
\quad(\mathrm{kg})\end{array}$} & \multirow{2}{*}{$\begin{array}{c}\text { Cement } \\
(\mathrm{kg})\end{array}$} & \multirow{2}{*}{$\begin{array}{l}\text { FA } \\
(\mathrm{kg})\end{array}$} & \multirow{2}{*}{$\begin{array}{l}\text { HRWRA } \\
(\mathrm{kg})\end{array}$} & \multicolumn{2}{|c|}{ Recycled aggregate } \\
\hline & & & & & & & Weight $(\mathrm{kg})$ & Percentage (\%) \\
\hline RCA-SCC-1 & 0.46 & 210 & 736.2 & 305 & 144 & 3.143 & 0 & 0 \\
\hline RCA-SCC-2 & 0.46 & 210 & 736.2 & 305 & 144 & 3.143 & 399 & 50 \\
\hline RCA-SCC-3 & 0.46 & 210 & 736.2 & 305 & 144 & 3.143 & 798 & 100 \\
\hline RCA-SCC-4 & 0.32 & 176 & 936.2 & 395 & 151 & 1.638 & 798 & 100 \\
\hline RCA-SCC-5 & 0.28 & 164 & 736.2 & 477 & 113 & 1.77 & 798 & 100 \\
\hline
\end{tabular}




\section{Experimental results and analysis}

\subsection{Fresh state behavior}

The experimental results of the 16 groups of RCA-SCC mixtures in fresh state are summarized in Table 4.

It is found that the slump flow diameters of RCA-SCC mixtures for each group are greater than $550 \mathrm{~mm}$ which is the minimum slump flow requirement of SCC (Ferraris et al., 2000). However, the difference between the J-ring slump and the slump flow diameter is greater than $50 \mathrm{~mm}$ for groups Z12 and Z15, which exceeds the recommended value of lower limit $50 \mathrm{~mm}$ (EFNARC, 2005). Therefore, the proportions in mix design corresponding to these two groups are not recommended for SCC mixture since the poor workability may be encountered. Further, investigation of the influence of the RCA replacement ratio on the J-ring flow indicates that increasing the RCA replacement ratio to $30 \%$ will enhance the passing ability of the fresh RCA-SCC mixture in different levels for the W/C ratios of $0.28,0.32$ and 0.38 . Further increasing of the RCA replacement ratio may result in varying trends under different
$\mathrm{W} / \mathrm{C}$ ratios. The dependence of the fresh properties of the RCA-SCC mixture with a specific W/C ratio 0.46 on RA replacement ratio is not obvious, as shown in Figure 4a. Overall, the fresh properties exhibit the positive dependence on the RCA replacement ratio, which exhibits the opposite trends observed for RCA-SCC with the size of $14 \mathrm{~mm}$ coarse RCA (Aslani et al., 2018). Differently, the particle grading distribution of the RCA used in this study is continuous in accordance to the distribution of the natural aggregates. With increase of the percentage of the RCA replacement ratio, the porosity of RCA-SCC mixture increases and the high water absorption capacity is raised (Khodair \& Bommareddy, 2017). Whilst, the pre-soaked treatment of the RCA compensates the additional consumption of water in concrete mixture compared with the untreated natural coarse aggregates. Thus, the flowability of the RCA-SCC mixture can be effectively achieved. An increase of $74 \mathrm{~mm}$ in J-ring flow of RCA-SCC with 100\% coarse RCA is achieved compared with that of natural aggregate SCC, but a decrease of $20 \mathrm{~mm}$ than the maximum value is observed for the case of $\mathrm{W} / \mathrm{C}$ ratio of 0.32 .

Table 4. Experimental results of the fresh state properties of RCA-SCC mixes

\begin{tabular}{|c|c|c|c|c|c|}
\hline No. & W/C ratio & $\mathrm{T}_{500}(\mathrm{~s})$ & Slump flow $(\mathrm{mm})$ & J-ring $(\mathrm{mm})$ & Segregation ratio (\%) \\
\hline Z1 & 0.28 & 5.7 & 630 & 590 & 17.2 \\
\hline Z2 & 0.28 & 5.5 & 725 & 702 & 14.6 \\
\hline Z3 & 0.28 & 5.9 & 690 & 678 & 16.2 \\
\hline Z4 & 0.28 & 6.2 & 670 & 655 & 13.8 \\
\hline Z5 & 0.32 & 7.5 & 613 & 566 & 10.2 \\
\hline Z6 & 0.32 & 8.3 & 600 & 551 & 9.6 \\
\hline Z7 & 0.32 & 9.3 & 670 & 625 & 9.5 \\
\hline Z8 & 0.32 & 8.0 & 690 & 645 & 9.8 \\
\hline Z9 & 0.38 & 13.2 & 560 & 520 & 9.2 \\
\hline Z10 & 0.38 & 9.4 & 605 & 555 & 9.9 \\
\hline Z11 & 0.38 & 15.4 & 570 & 540 & 8.0 \\
\hline Z12 & 0.38 & 13 & 620 & 555 & 11.4 \\
\hline Z13 & 0.46 & 6.8 & 650 & 605 & 8.8 \\
\hline Z14 & 0.46 & 10.1 & 660 & 616 & 8.5 \\
\hline Z15 & 0.46 & 6.2 & 670 & 625 & 590 \\
\hline Z16 & 0.46 & 8.3 & & & 7.3 \\
\hline
\end{tabular}

a)

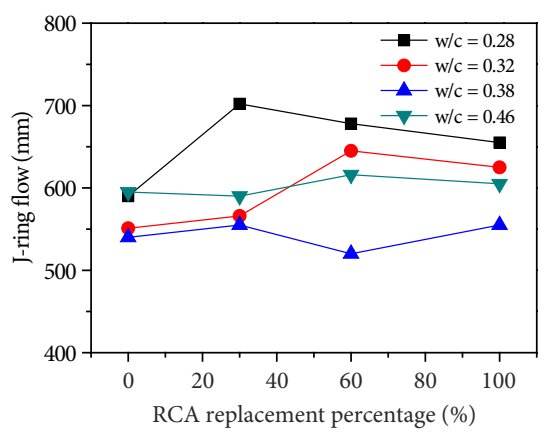

b)

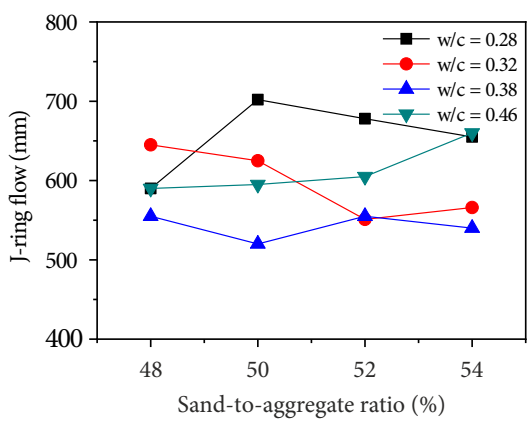

c)

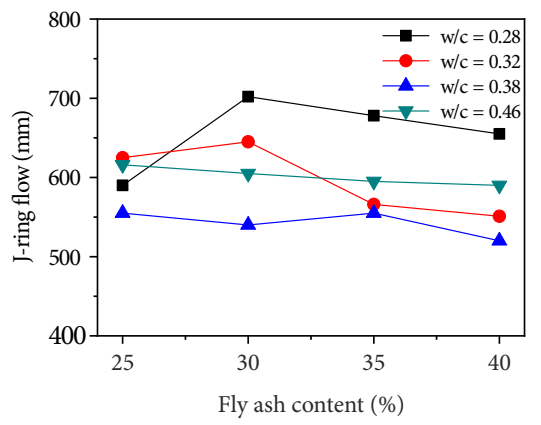

Figure 4. Effect of: a - RCA replacement percentage, $\mathrm{b}$ - sand to aggregate (S/A) ratio and $\mathrm{c}$ - fly ash content on J-ring flow of RCA-SCC mixture 
For the RCA-SCC mixture with W/C ratios of 0.38 and 0.46 , the influence of RCA replacement ratio can be basically neglected on the J-ring flow.

Further, investigation of the effect of the S/A ratio on J-ring flow of the RCA-SCC mixture indicates that the trends of the J-ring flow vary with different levels of W/C ratio, as shown in Figure $4 \mathrm{~b}$. For the case of W/C ratio of 0.28 , a similar trend as that of the RCA replacement ratio effect can be observed. But for RCA-SCC mixture with $\mathrm{W} / \mathrm{C}$ ratio of 0.32 , the J-ring flow decreases with an increase of S/A ratio up to $52 \%$. Then, the J-ring flow slightly improves when the S/A ratio is added to $54 \%$ in mixture, whereas the J-ring flow is almost independent of S/A ratio for RCA-SCC mixture with W/C ratio of 0.38 . However, a positive correlation between the J-ring slump flow and the natural sand content is exhibited for the RCA-SCC mixture with W/C ratio of 0.46 . Clearly, the mix of S/A ratio to achieve the available passing ability of RCA-SCC mixture varies with the W/C ratio. For RCA-SCC mixture with a high W/C ratio, a low sand content may weaken the lubrication effect among aggregates adhered with thin mortar, and thus a comparatively high sand ratio is needed to enhance the flowability.

The effect of FA content on the J-ring flow of RCASCC mixture is the same with W/C ratios of 0.28 and 0.32 , as shown in Figure 4c. Moreover, FA content has a limited effect on J-ring flow at $\mathrm{W} / \mathrm{C}$ ratios of 0.38 and 0.46 . An explanation is that the increasing W/C ratio partly compensates for the water absorption for high percentages of FA which is treated as the replacement for cement (Kou et al., 2007). By carrying out the parametrical analysis, it is noticed that for the RCA-SCC mixture with different $\mathrm{W} / \mathrm{C}$ ratios, the J-ring flow has distinctly different dependence on the experimental parameters, i.e., RCA replacement ratio, S/A ratio and FA content. Namely, to achieve similar flowability or passing ability, an effective $\mathrm{W} / \mathrm{C}$ ratio can dominate the proportions of contents in mix design of RCA-SCC mixture (Silva et al., 2018). Besides, the test findings about fresh properties of the RCA-SCC mixture reveal that using RCA in SCC to properly replace the natural aggregates is deemed to be appropriate and accepted for obtaining the feasible RCA concrete in civil engineering applications.

\subsection{Compressive strength of RCA-SCC mixture}

The compressive strengths of 16 RCA-SCC mixtures are listed in Table 5. It is found that for a certain $\mathrm{W} / \mathrm{C}$ ratio, the compressive strength of the RCA-SCC increases with the curing ages until to the best performance after 28 days. Among the 16 RCA-SCC specimens, group Z1 has a maximum compressive strength of $64 \mathrm{MPa}$ at curing age of 28 days whereas the minimum strength is only $29.6 \mathrm{MPa}$ for group Z13 at a same curing age.

This implies that the mix proportion has a considerable effect on the compressive performance of RCA-SCC. Therefore, a desirable performance of RCA-SCC is expected to be achieved by appropriately modifying the mix proportions. To propose a design guideline, a thorough understanding of the effect of variables associated in RCASCC mixtures is required. As shown in Figure 5a, for a given W/C ratio, the compressive strength of RCA-SCC decreases with the increase of RCA replacement ratio because the weak adhesion between the old and new mortar in RCA-SCC is expanded as the RCA replacement ratio increases. Besides, a large number of pores and cracks introduced during crushing process (Xiao et al., 2012) can further reduce the strength of RCA-SCC in some extend. Basically, for a certain RCA replacement ratio, the higher $\mathrm{W} / \mathrm{C}$ ratio corresponds to the lower compressive strength of the RCA-SCC mixture. This is due to the decreasing cohesiveness or stickiness between the RCA and the relatively diluted cement mortar of RCA-SCC mixture (Etxeberria et al., 2006).

The effect of natural sand content on the compressive strength of RCA-SCC exhibits large dispersity with varying W/C ratios, as shown in Figure 5b. For W/C ratio of 0.28 , the compressive strength decreases with the raise of natural sand content whereas the opposite case is observed for the RCA-SCC with W/C ratio of 0.32. However, when $\mathrm{W} / \mathrm{C}$ ratios are prepared as 0.38 and 0.46 , variation of compressive strength with the increase of sand content is not monotonic, but increases firstly and then decreases for $\mathrm{W} / \mathrm{C}$ ratio of 0.38 , whereas the reverse case for $\mathrm{W} / \mathrm{C}$ ratio of 0.46 is acquired.

Similar with that of S/A ratio, the effect of FA on the compressive strength of the RCA-SCC is also individual. The linear reduction of the compressive strength is found for RCA-SCC with W/C ratio of 0.28, as shown in Figure 5c.

Table 5. Experimental results of the hardened properties of RCA-SCC mixtures

\begin{tabular}{|c|c|c|c|c|c|}
\hline \multirow{2}{*}{ No. } & \multirow{2}{*}{$\begin{array}{l}\mathrm{W} / \mathrm{C} \\
\text { ratio }\end{array}$} & \multicolumn{3}{|c|}{ Compressive strength $(\mathrm{MPa})$} & \multirow{2}{*}{$\begin{array}{c}\text { Standard } \\
\text { deviation } \\
(\mathrm{MPa})\end{array}$} \\
\hline & & $7 d$ & $14 \mathrm{~d}$ & $28 \mathrm{~d}$ & \\
\hline $\mathrm{Z1}$ & 0.28 & 42 & 47.9 & 64 & 9.30 \\
\hline $\mathrm{Z2}$ & 0.28 & 25.3 & 27.1 & 51.5 & 11.9 \\
\hline $\mathrm{Z3}$ & 0.28 & 24.5 & 28 & 49 & 10.8 \\
\hline $\mathrm{Z} 4$ & 0.28 & 19.1 & 25 & 40.5 & 9.02 \\
\hline $\mathrm{Z} 5$ & 0.32 & 34.2 & 40 & 53.2 & 7.95 \\
\hline Z6 & 0.32 & 21.8 & 29.5 & 48 & 11.0 \\
\hline $\mathrm{Z7}$ & 0.32 & 25 & 28 & 46.2 & 9.37 \\
\hline $\mathrm{Z8}$ & 0.32 & 23.4 & 26.2 & 43.2 & 8.75 \\
\hline Z9 & 0.38 & 36.9 & 42.1 & 56 & 8.06 \\
\hline $\mathrm{Z10}$ & 0.38 & 29.4 & 33.5 & 44.7 & 6.47 \\
\hline $\mathrm{Z11}$ & 0.38 & 25.3 & 28.8 & 38.5 & 5.58 \\
\hline $\mathrm{Z12}$ & 0.38 & 27.5 & 31.4 & 41.8 & 6.04 \\
\hline $\mathrm{Z13}$ & 0.46 & 19.5 & 22.2 & 29.6 & 4.27 \\
\hline Z14 & 0.46 & 27.5 & 31.4 & 41.8 & 6.04 \\
\hline $\mathrm{Z15}$ & 0.46 & 24 & 27.4 & 36.5 & 5.28 \\
\hline Z16 & 0.46 & 22 & 25.1 & 33.4 & 4.81 \\
\hline
\end{tabular}


Under the condition of $\mathrm{W} / \mathrm{C}$ ratio of 0.32 , the compressive strength undulates around about $50 \mathrm{MPa}$ with variation of the FA content. For the RCA-SCC with 0.38 and 0.46 $\mathrm{W} / \mathrm{C}$ ratios, the variations of compressive strength exhibit two stages that increase with the FA content firstly but decrease with further increase of the FA content after the content of FA reaches $30 \%$ within concrete mixture.

\subsection{Compressive behavior of RCA-SCC columns}

\subsubsection{Failure modes}

At the early stage of the compressive process, the RCASCC columns are in the elastic stage and both of the longitudinal and lateral strains increase linearly. Obvious deformation is not observed on the surface of specimen. As the load increases to a critical value, cracks start to arise on the surface of the RCA-SCC columns, and then the crack propagations are in random manners due to the heterogeneity of the RCA-SCC column. Meanwhile, the deviation between longitudinal strain and the lateral strain begins to happen, and the specimens enter into the elasticplastic stage. As the load increases continuously, the rapidly increasing strain levels are initiated due to the high stress concentration at the prior crack points (Guo et al., 1982). As the compression process continues, the sharp longitudinal cracks are observed all around the specimens and the number of the cracks grows constantly when the load is up to $70 \%$ of the ultimate bearing capacity of the RCA-SCC specimens. The development of cracks accelerates as the load reaches $85 \%$ the ultimate bearing capacity of the specimens. Further, the crack growth speed rises with increase of RCA replacement ratio. The typical failure modes of the cracks propagation of the specimens are demonstrated in Figure 6. It indicates that the failure a)

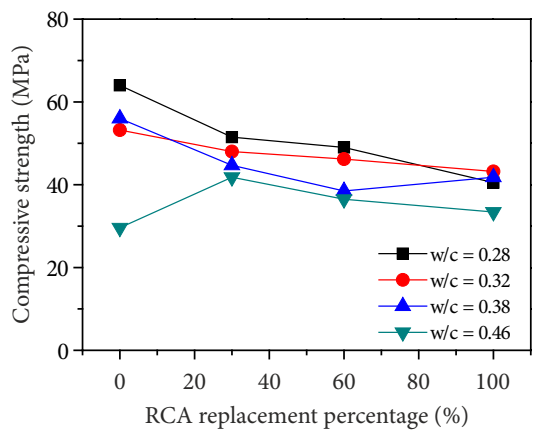

b)

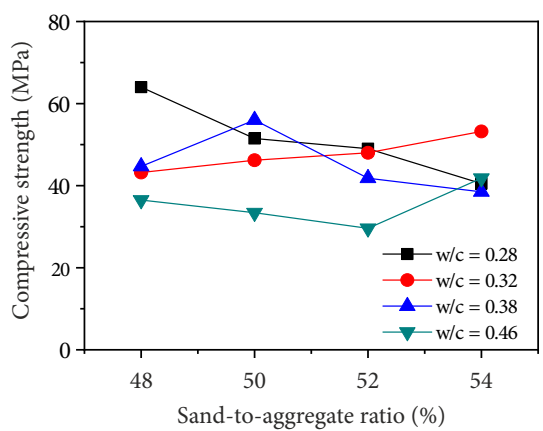

c)

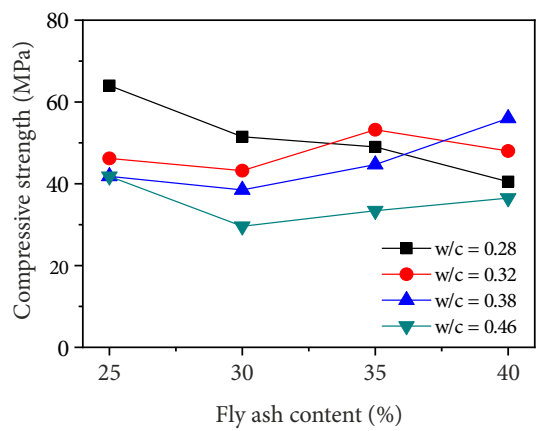

Figure 5. Effect of: a - RCA replacement ratio, b - sand-to-aggregate (S/A) ratio and c - fly ash content on compressive strength of RCA-SCC mixture

a) RCA-SCC-1

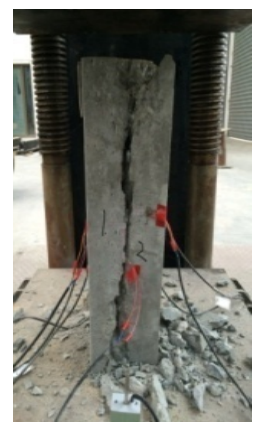

d) RCA-SCC-4

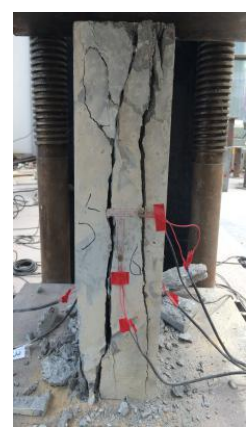

b) RCA-SCC-2
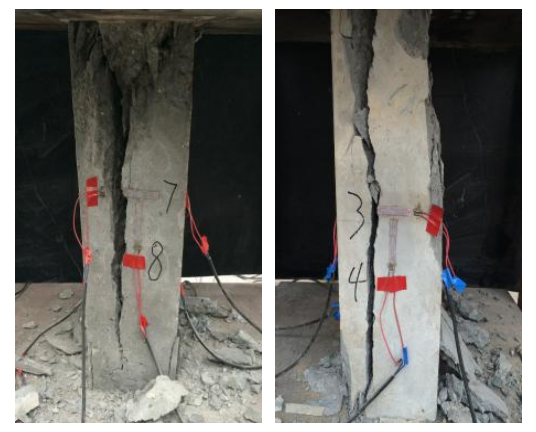

c) RCA-SCC-3

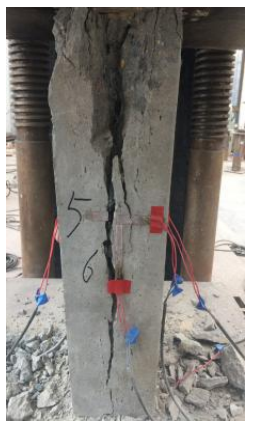

e) RCA-SCC-5

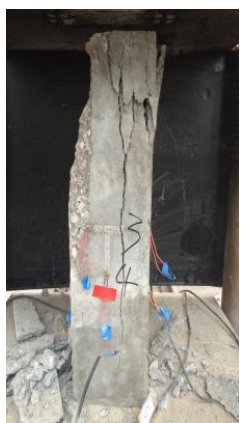

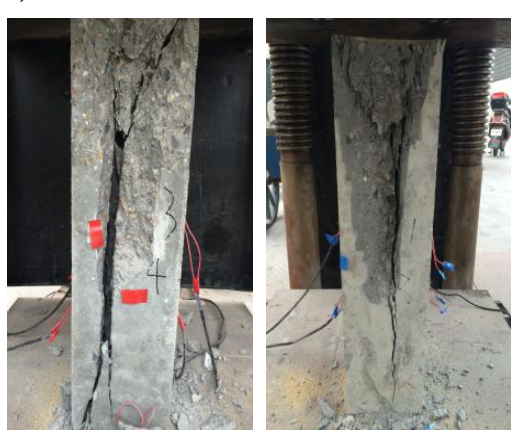
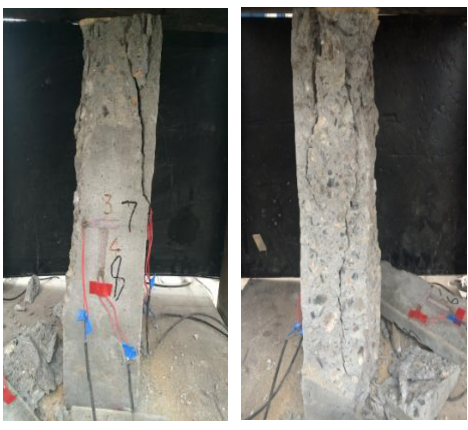

Figure 6. The failure modes of square RCA-SCC columns under compression 
modes of the specimens with different RCA replacement ratio are basically identical, and all of the failure modes are similar to that of the conventional concrete. Finally, the longitudinal cracks divide the RCA-SCC columns into several short columns which suffer brittle failures as the ultimate bearing capacity is reached.

\subsubsection{Peak stress}

The peak stress, which is defined as the first stress peak appears on the stress-strain curve of the RCA-SCC column, is a crucial parameter to evaluate the ultimate strength of the specimens. The effect of $\mathrm{W} / \mathrm{C}$ ratio on the peak stress is presented in Figure 7a. This figure indicates that the peak stress of the specimens decreases with increase of W/C ratio. It is understood that a higher $\mathrm{W} / \mathrm{C}$ ratio may result in a less cohesive mixture of concrete as all other factors are equal (Daczko, 2012). Therefore, the decreased cohesiveness between the RCA and the relatively thin cement mortar leads to the decreasing trend of the peak stress of the RCA-SCC columns with high W/C ratio, which is in agreement with that of the compressive strength of RCASCC mixture discussed previously.

Similar decreasing trend of the peak stress can be found when considering the effect of RCA replacement ratio on the mechanical property of the RCA-SCC column, as shown in Figure 7b. The decrease of the peak stress with an increase of RCA replacement ratio is due to the fact that the expanded weak adhesion between the RCA and the old and new mortar in RCA-SCC mixture is raised. In addition, the existence of micro pores and
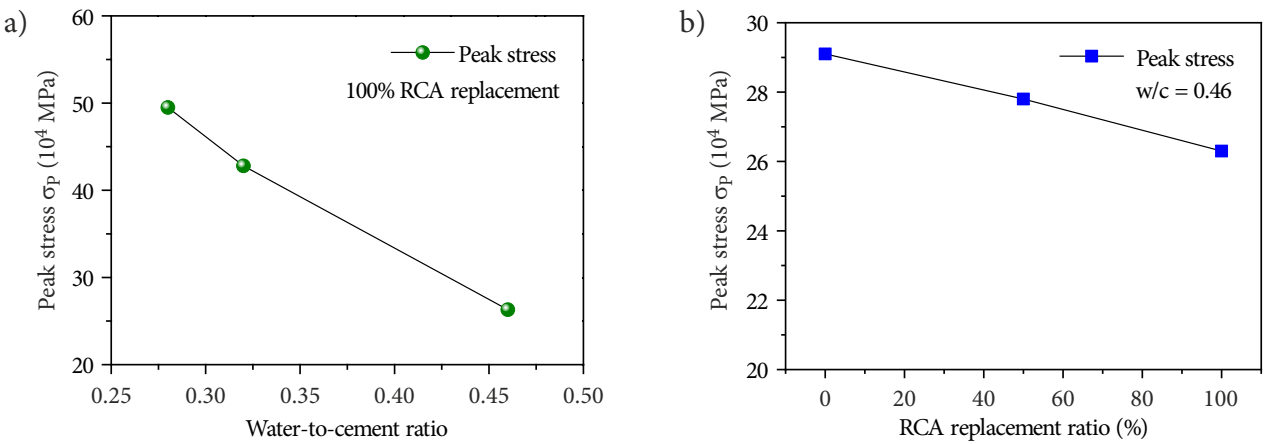

cracks formed during crushing process (Xiao et al., 2012) of RCA will further result in the reduction the strength of RCA-SCC columns.

\subsubsection{Peak strain}

The variation of the longitudinal and lateral peak strains which correspond to the peak stress of RCA-SCC column with W/C ratio is shown in Figure 8a. This figure indicates that both the longitudinal strain and lateral strain decrease with an increase of W/C ratio, which is in accordance with the trend of peak stress. Accordingly, the low peak strains are attributed to the low ductility of the specimens with high W/C ratio.

It should be noticed that the peak strains of the RCASCC columns develop almost linearly with increase of the RCA replacement ratio, as shown in Figure 8b. Usually, RCA is obtained by crushing and sieving the waste concrete. Herein, the RCA-SCC columns tend to deform more easily than the conventional concrete column since the RCA involved in RCA-SCC columns is likely to have an initial damage formed in the secondary process. Besides, it also can be found that the longitudinal strain increases more rapidly than the lateral strain with the rise of the RCA replacement ratio.

\subsubsection{Elastic modulus}

The relation between the measured elastic modulus of the RCA-SCC columns and the W/C ratio is shown in Figure 9a. Similar with the cylinder specimen, the measured values of elastic elasticity of the prism RCA-SCC specimens were

Figure 7. Effect of: $a$ - Water-to-cement ratio and b - RCA replacement ratio on peak stress

a)

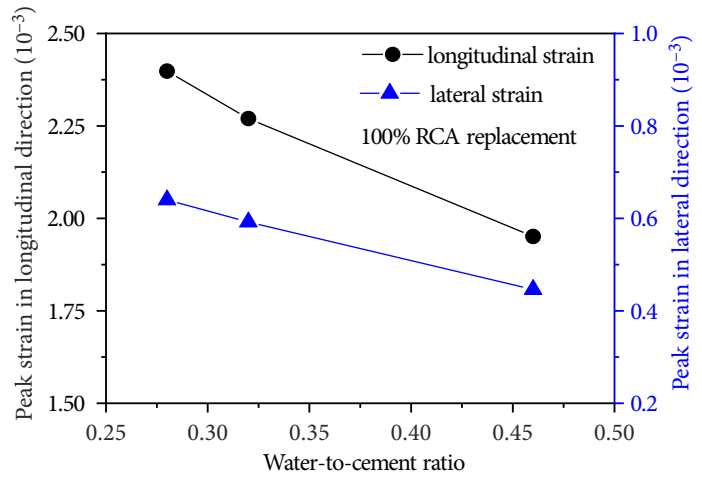

b)

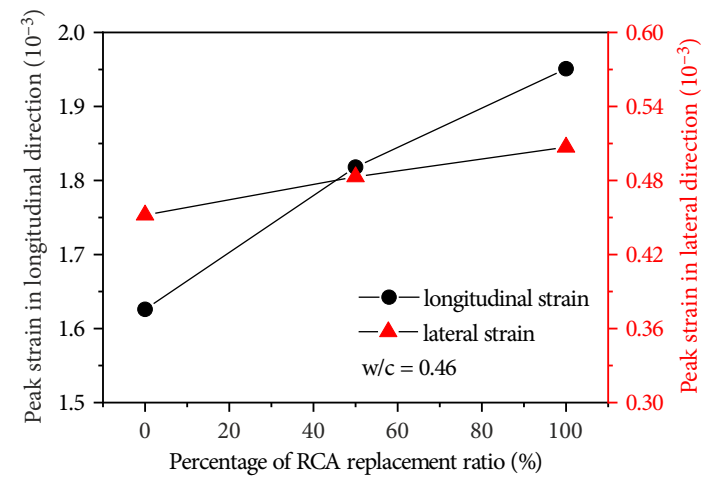

Figure 8. Effect of: a - Water-to-cement ratio and b - RCA replacement ratio on the peak strains of RCA-SCC column 
determined in accordance with Italian Standard UNI EN 12390-13 (Ente Nazionale Italiano di Unificazione [UNI], 2013). Clearly, the elastic modulus decreases steadily with the enhancement of W/C ratio. A higher W/C ratio corresponds to a less usage of cement, which leads to a reduction in the cohesiveness of the RCA-SCC mixture. Therefore, the stiffness of RCA-SCC column is attenuated.

Further, the elastic modulus of the RCA-SCC column presents a slight decrease with an increase in RCA replacement ratio, as shown in Figure 9b. Generally, the old mortar that is attached on the surface of the primary aggregate in RCA-SCC has comparatively low elastic modulus. As the natural aggregate is replaced by RCA which consists of a large amount of attached cement mortar, the porosity of RCA-SCC mixture would increase, and a reduction in elastic modulus is found (Gómez-Soberón, 2002). It is also noticed that the elastic modulus drops just about $12 \%$ when the natural aggregate is totally replaced by RCA. Even only $3 \%$ reduction in the elastic modulus of concrete containing RCA is reported (Rahal, 2007). Herein, a general awareness is that RCA-SCC column made with RCA will not reduce the stiffness definitely if the W/C ratio is appropriate, and an adequate adhesion between the old and the new mortar can be achieved.

\subsubsection{Poisson's ratio}

The Poisson's ratio, which is defined as the ratio of the lateral strain to the longitudinal strain, is an index to evaluate the lateral deformation capacity of the RCA-SCC columns. Obviously, the Poisson's ratio varies with the stress level during compression. In this study, the Poisson's ratio of

a)

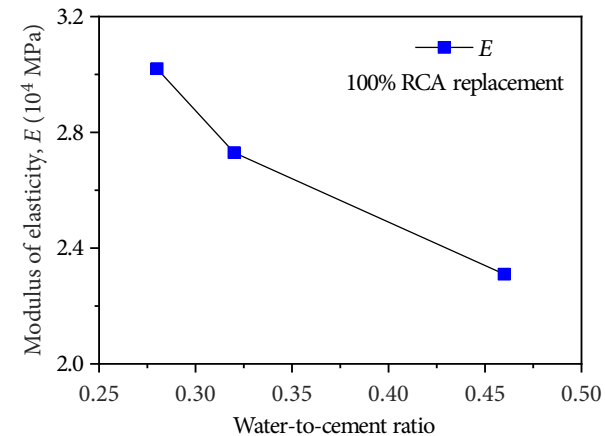

the RCA-SCC columns is determined as the stress reaches three times the peak stress.

The variation of Poisson's ratio with $\mathrm{W} / \mathrm{C}$ ratio and RCA replacement ratio indicates that the Poisson's ratio of RCA-SCC columns is basically independent of W/C ratio, as shown in Figure 10a. Differently, the Poisson's ratio of RCA-SCC column decreases almost linearly with the increase of the RCA replacement ratio, as shown in Figure 10b. Compared with the natural aggregate, the RCA has considerable water absorption capacity (Lotfi et al., 2015; Ferreira et al., 2011). Yet, due to the pre-soaking treatment of the raw RCA, the same effective $\mathrm{W} / \mathrm{C}$ ratio of specimens could be basically achieved. Hence, with the increase in RCA replacement ratio, the bonding surface area between the rough RCA and cement was enlarged, resulting in relatively lower transverse confinement of the RCA-SCC column and decreased the Poisson's ratio.

\subsubsection{Compressive stress-strain curves}

The stress-strain relations of the RCA-SCC columns with different concrete strength grades and different RCA replacement ratios are presented in Figure 11. Two obvious stages can be observed on the stress-strain curves, i.e. the elastic stage and the elastoplastic stage. At the initial stage of loading, the stress develops linearly as the compression strain increases, and the specimen is in the elastic state without any damages induced. If the compression load is released in this stage, the specimens can nearly back to the initial state. Moreover, it can be observed from the stressstrain curves that the elastic stage extends when the concrete strength enhances. However, the RCA replacement

b)

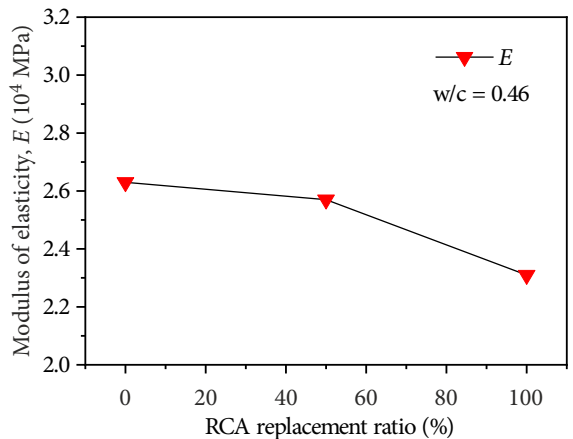

Figure 9. Effect of: $a$ - Water-to-cement ratio and b - RCA replacement percentage on elastic modulus of RCA-SCC column
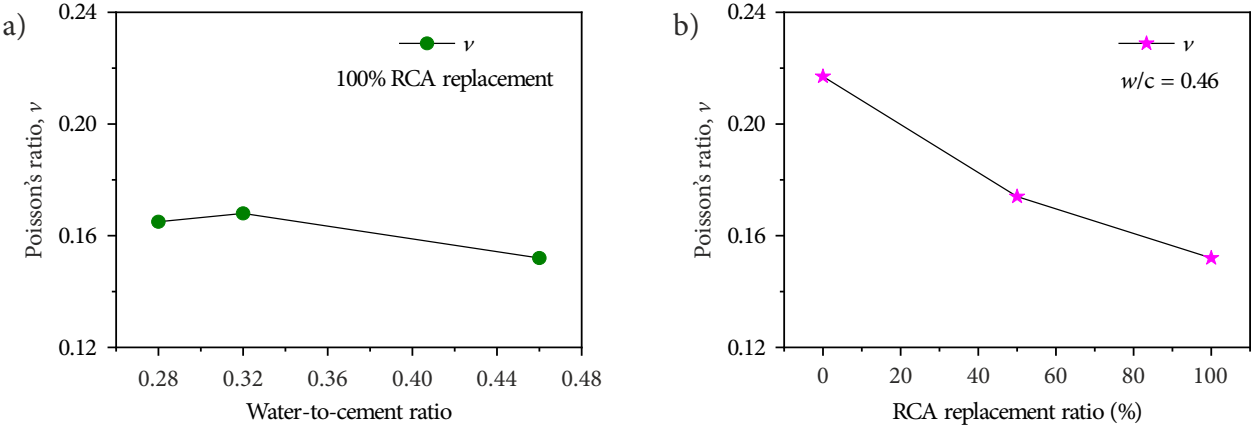

Figure 10. Effect of: a - Water-to-cement ratio and b - RCA replacement ratio on Poisson's ratio of RCA-SCC column 
ratio seemingly has opposite effect on the elastic stage a higher RCA replacement ratio corresponds to a shorter elastic stage and a gentler slope of the linear curves. As the load increases, the linear relation between the stress and the strain cannot be held, and the specimen enters into elastoplastic stage. Cracks appear in this stage and the growth rate of the strains accelerates correspondingly. Since the RCA-SCC has excellent self-consolidating capacity, pores within the mixture are greatly eliminated (Tam et al., 2005), which results in a smooth transition in the ascending branch on the stress-strain curves of the specimens. With further increase of loading, the strains raise dramatically within almost constant stress. The higher strength of concrete leads to a higher growth rate of the strains whereas the RCA replacement ratio has reverse trend. It implies that the higher RCA replacement ratio makes the specimens tend to become more brittle and weaker. Partly, concrete with high strength grade can compensate the reduction of compressive strength of the specimens for the high RCA replacement ratio, as illustrated in Figure 11.

\section{Theoretical model for predicting the mechanical behavior of RCA-SCC column}

\subsection{Peak stress}

The test data obtained from the present study and the experimental data from the published literature (Shi et al., 2012; Ma et al., 2010; Xiao, 2008; Wu et al., 2009; Lin, 2007) were used to develop a regression model between the peak stress of RCA-SCC members and the cubic compressive strength of RCA-SCC:

$$
\sigma_{\mathrm{cp}}=0.0013 f_{\mathrm{cu}}^{2}+0.6854 f_{\mathrm{cu}}+0.382,
$$

where $\sigma_{\mathrm{cp}}$ is the peak stress of RCA-SCC, $f_{\mathrm{cu}}$ is the cubic compressive strength of RCA-SCC. Figure 12 shows that the experimental data basically fall on the predicted locus, and the formula can be approximately used to evaluated the ultimate strength of RCA-SCC columns.

\subsection{Elastic modulus}

Based on the test results, the dependence of the elastic modulus of the RCA-SCC columns on the cubic compressive strength of the RCA-SCC was demonstrated, as shown in Figure 13. Roughly, the elastic modulus has a positive correlation with the cubic compressive strength of the RCA-SCC. The microcracks within RCA can be introduced during the crushing process of the waste concrete cubes, and also may be raised at the interfacial transition zones between the old attached mortar and the original aggregate. Hence, the stiffness as well as the strength of composite members containing RCA at both the precracking and damaged stages will be affected consistently by the existence of microcracks. Quantitatively, together with previously reported experimental data (Xiao, 2008; Xing \& Zhou, 1998; Zhang, 2009; Hu et al., 2009; Xing et al., 1999; Xia et al., 2009), a formula was developed as:

$$
E_{\mathrm{c}}=\frac{10^{5} f_{\mathrm{cu}}}{3.27 f_{\mathrm{cu}}+26.5}
$$

where $E_{\mathrm{c}}$ is the elastic modulus of RCA-SCC columns. It transpires that the above model can well predict the elastic modulus of RCA-SCC columns, as shown in Figure 13.

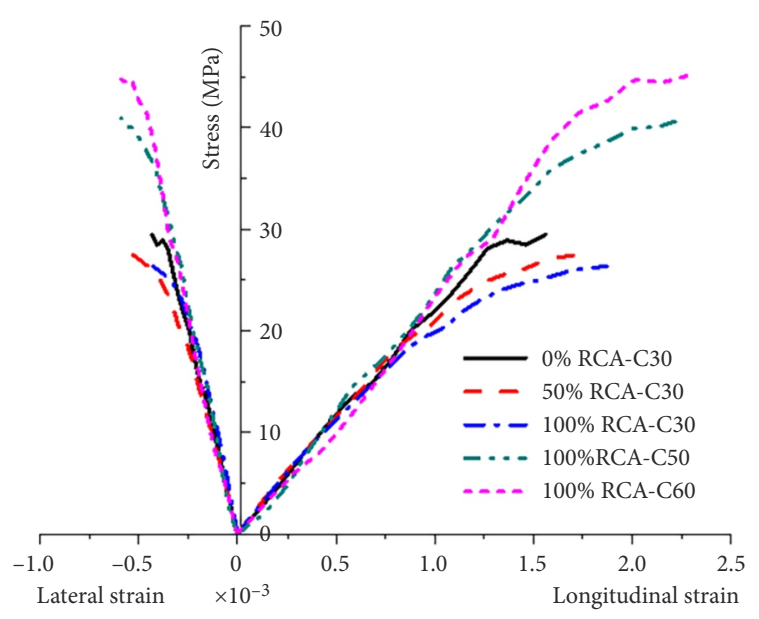

Figure 11. Typical stress-strain curves of different RCA-SCC columns

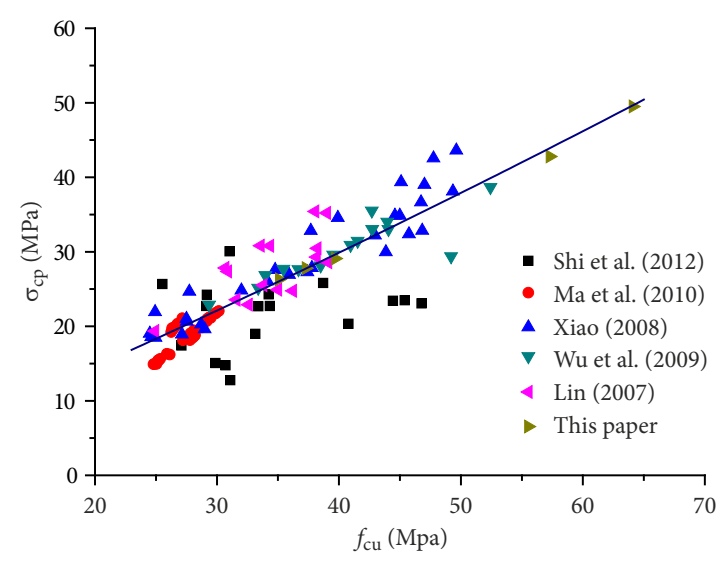

Figure 12. Relationship between peak stress and $a_{1}=2.125-1.171 \gamma-0.0035 f_{\mathrm{ck}}$

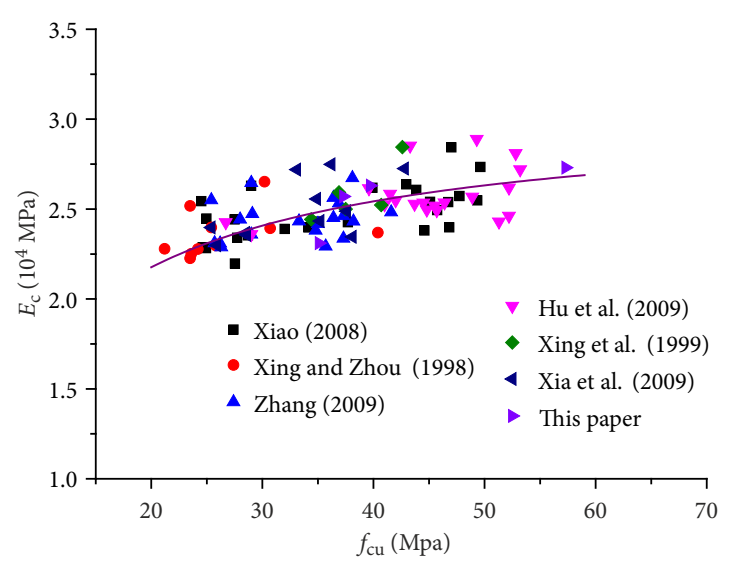

Figure 13. Relationship between elastic modulus and $f_{\text {cu }}$ 


\subsection{Peak strain}

According to the test results in this paper, the peak strain of the RCA-SCC columns is larger than that of ordinary concrete. This is mainly due to the lower elastic modulus of the RCA and the larger deformation of the RCA itself. Through regression analysis of the test data measured in this study and acquired from other tests (Lin, 2007; $\mathrm{Hu}$ et al., 2009; Xia et al., 2009; Wang, 2013; Wu et al., 2016a), the predicted expressions of longitudinal peak strain $\varepsilon_{\mathrm{cp}}$ and the lateral peak strain $\varepsilon_{\mathrm{clp}}$ of the RCA-SCC columns are determined as:

$$
\begin{aligned}
& \varepsilon_{\mathrm{cp}}=0.0002 f_{\mathrm{ck}}^{2}-0.011 f_{\mathrm{ck}}+0.6039 ; \\
& \varepsilon_{\mathrm{cpl}}=0.0071 f_{\mathrm{ck}}+0.2858
\end{aligned}
$$

The values of the peak strains measured in the present study are plotted against the cubic compressive strength of RCA-SCC columns alongside the corresponding available test data, as shown in Figure 14 and Figure 15. Compared with the large dispersion of the test data from the published literature, the prediction models can well capture the dependence of the peak strains on the cubic compressive strength of the RCA-SCC columns.

\subsection{Poisson's ratio}

Poisson's ratio $v$ is defined as the absolute value of the ratio of the lateral strain to the longitudinal strain of concrete, and it is an important index to measure the lateral deformation ability of concrete. Considering the nonconstant Poisson's ratio of concrete under different stress states, in this study, it is suggested that the Poisson's ratio of the RCA-SCC columns should be taken as the Poisson's ratio when the stress of RCA-SCC columns is $0.3 \sigma_{\mathrm{cp}}$. Together with the test data determined in this study and the available experimental data (Wang, 2013; Wu et al., 2016b; Chen, 2016; Xu et al., 2012; Zhang et al., 2015; Huang, 2012), a regression model to establish the relationship between the Poisson's ratio $v$ and the peak stress $\sigma_{\mathrm{cp}}$ of RCA-SCC columns is developed as:

$$
\mathrm{v}=-8 \times 10^{-5} \sigma_{\mathrm{cp}}^{2}+0.0066 \sigma_{\mathrm{cp}}+0.0584 \text {. }
$$

The variation of the Poisson's ratio with the peak stress of RCA-SCC columns is shown in Figure 16. Actually, by taking the discreteness of the specimens into consideration, the change of the Poisson's ratio within a wide range of the peak stress is not obvious.

\subsection{Stress-strain relation model}

Based on the experimental study and the formula recommended by Guo et al. (1982), the stress-strain relationship model of the RCA-SCC columns is established. For the longitudinal direction, the stress-strain relation can be expressed as:

$$
y_{1}=a_{1} x_{1}+\left(3-2 a_{1}\right) x_{1}^{2}+\left(a_{1}-2\right) x_{1}^{3} .
$$

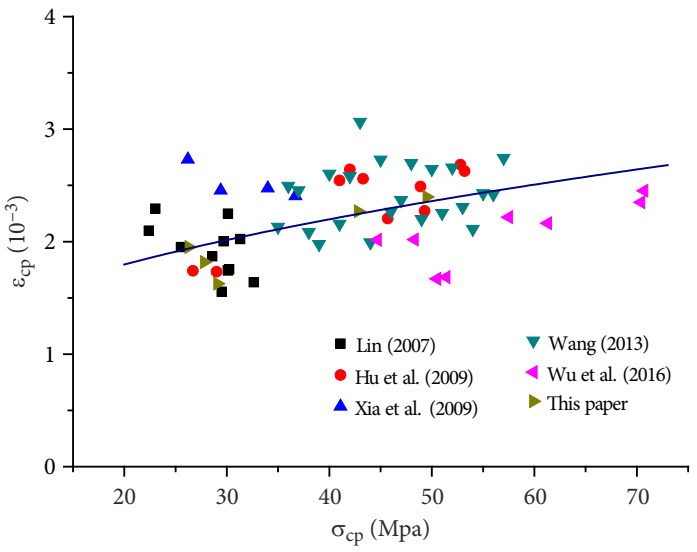

Figure 14. Relationship between longitudinal peak strain and peak stress

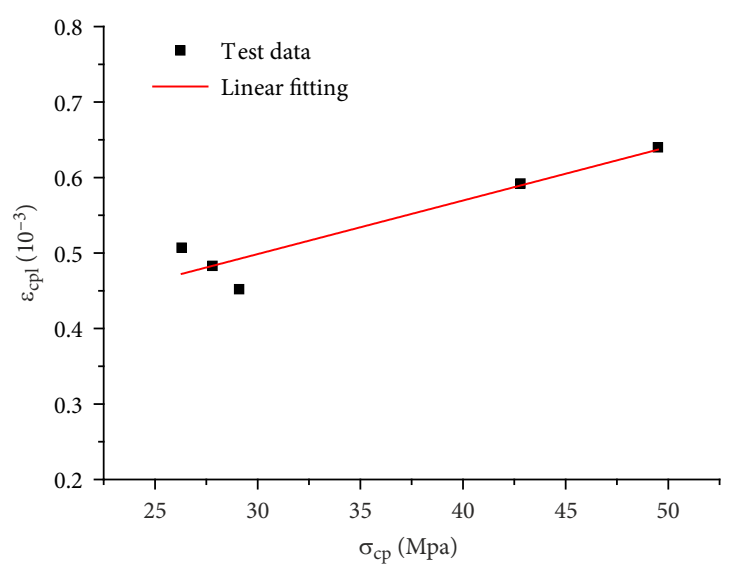

Figure 15. Relationship between lateral peak strain and peak stress

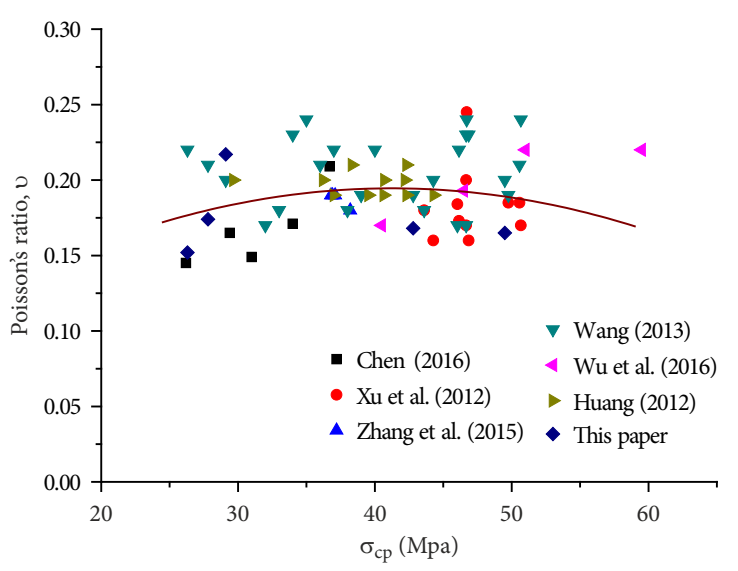

Figure 16. Relationship between Poisson's ratio and peak stress

Whereas, the lateral stress-stain relation of the RCASCC columns can be described in a similar form as:

$$
y_{2}=a_{2} x_{2}+\left(3-2 a_{2}\right) x_{2}^{2}+\left(a_{2}-2\right) x_{2}^{3},
$$

where $x_{1}=\frac{\varepsilon_{\mathrm{c}}}{\varepsilon_{\mathrm{cp}}}, x_{2}=\frac{\varepsilon_{\mathrm{cl}}}{\varepsilon_{\mathrm{clp}}}, y=\frac{\sigma_{\mathrm{c}}}{\sigma_{\mathrm{cp}}}, \varepsilon_{\mathrm{c}}$ and $\varepsilon_{\mathrm{cl}}$ are the longitudinal and the lateral strain of RCA-SCC columns, respectively, $\sigma_{\mathrm{c}}$ is the compressive stress of the RCA-SCC 
a) RCA-SCC-1

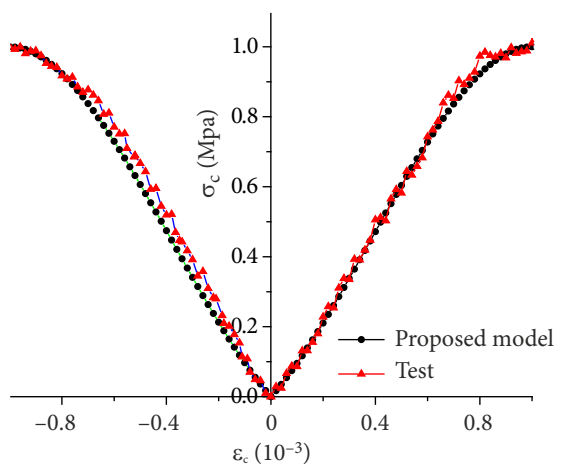

d) RCA-SCC-4

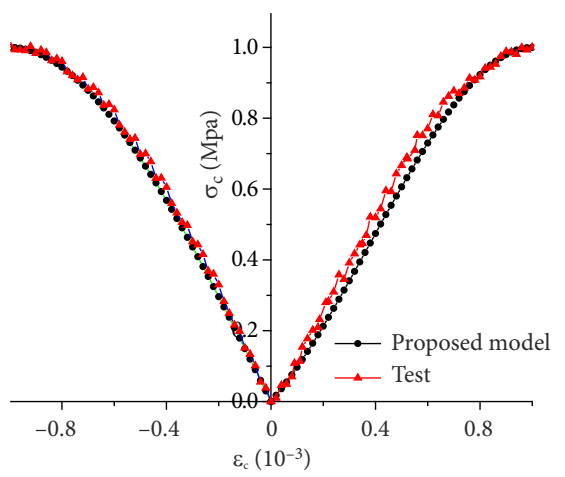

b) RCA-SCC-2

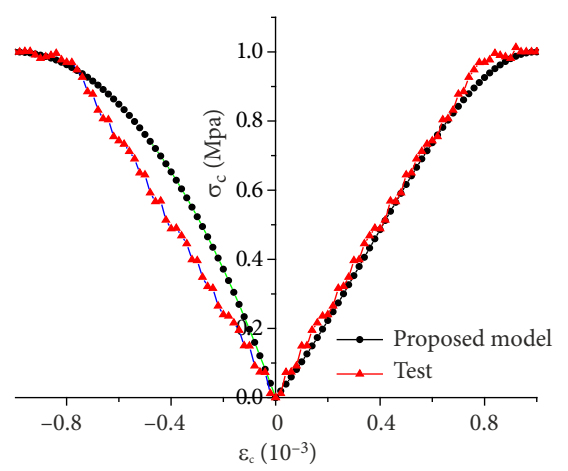

e) RCA-SCC-5

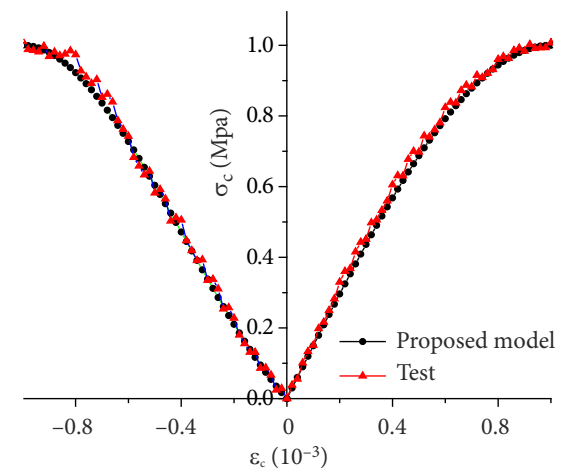

Figure 17. Comparison between measured and theoretical curves of the stress-strain relationship of RCA-SCC column

columns, $a_{1}$ and $a_{2}$ are the dimensionless longitudinal and the lateral parameters, respectively.

The parameter $a$ reflects the initial elastic modulus of the RCA-SCC columns. A small coefficient a refers to a little proportion of the plastic deformation to the total deformation when the stress reaches its peak value, and a high brittleness of the material. According to the test results in this paper, the relationship between the parameter $a$, the RCA replacement ratio $\gamma$ and the compressive strength of RCA-SCC columns $f_{\text {ck }}$ can be obtained by fitting with least square method as:

$$
\begin{aligned}
& a_{1}=2.125-1.171 \gamma-0.0035 f_{\mathrm{ck}} \\
& a_{2}=3.532-1.261 \gamma-0.0242 f_{\mathrm{ck}} .
\end{aligned}
$$

The comparison between the measured values and the theoretical curves of the stress-strain relationship of the RCA-SCC columns is shown in Figure 17. It can be seen that the measured values of the stress-strain relationships can be well fitted by the theoretical curves.

\section{Conclusions}

Self-consolidating concretes with different mix proportions were made by substituting the natural coarse aggregates with recycled aggregates that were derived from tested concretes. A continuous graded crushed waste concrete was obtained by using a series of recycling process. The influence of RCA replacement ratio, water-to-cement ratio, fly ash content and sand to aggregate ratio on the fluidity and the mechanical performance of recycled aggregate self-consolidating concrete were evaluated experimentally. The mechanical behavior of the RCA-SCC columns was further studied experimentally and theoretically. Based on the results, the following conclusions can be drawn:

(1) The fresh properties of the RCA-SCC mixture are mainly dominated by $\mathrm{W} / \mathrm{C}$ ratio since the cohesiveness between the RCA and the cement mortar is accordant with the dosage of cement. For given W/C ratio, the good flowability and passing ability of RCA-SCC can be achieved in mixtures with appropriate contents of RCA, sand and FA. The J-ring slump diameter of the fresh RCA-SCC mixture increases firstly with the increase of RCA replacement ratio, sand content and FA content, and then comes to the decreasing trend manners, when the $\mathrm{W} / \mathrm{C}$ ratio is 0.32 . However, when the $\mathrm{W} / \mathrm{C}$ ratio of RCA-SCC mixture is 0.38 , the J-ring slump diameter is almost independent of the proportional parameters.

(2) Overall, the RCA replacement ratio has negative effect on the compressive strength of the RCASCC due to the existence of the process-induced microcracks and the relatively weak zones between the old attached mortar and the original aggregates. The sand content and the fly ash content exhibit much significant influence on the harden properties of the RCA-SCC with low W/C ratio. 
(3) The failure modes of RCA-SCC columns are similar to those of conventional concrete columns. The initiated cracks propagate along the axial direction to distal ends and the accumulated longitudinal crack finally separates the column into several short columns. The ductile failure is observed for the RCA-SCC column, and a high bearing capacity is exhibited under the relatively larger longitudinal and lateral deformation. It is concluded that the RCA-SCC with partial or total replacement of natural aggregate with recycled aggregate is feasible for structural members by proper mix designing.

(4) The mechanical properties of RCA-SCC columns are quantitatively described by developing regression models based on the experimental results alongside with available test data. The theoretical predictions can well capture the changes of the considered mechanical properties (i.e., the peak stress, the peak strain, the elastic modulus, the Poisson's ratio and the stress-strain relation) that are determined from tests.

\section{Acknowledgements}

The authors wish to acknowledge the National Natural Science Foundation of China and Anhui University of Technology for the support for this research work. Also, the authors wish to acknowledge Jingcheng Engineering Quality Inspection Co. LTD for the supply of discarded concrete.

\section{Funding}

This work was supported by the National Natural Science Foundation of China [No. 52078001, 51878002, and 51578001]; Outstanding Youth Fund of Anhui Province [No. 2008085J29]; Key Research and Development Plan of Anhui Province [No. 1704a0802131], and the University Synergy Innovation Program of Anhui Province [No. GXXT-2019-005].

\section{Author contributions}

F.Y and W.H conceived the study and were responsible for the design and development of the data analysis. C.C.F, Y.F and S.S.B were responsible for data collection and analysis. C.C.F and S.L.W were responsible for data interpretation. F.Y wrote the first draft of the article.

\section{Disclosure statement}

Authors declare that they have not any competing financial, professional, or personal interests from other parties.

\section{References}

Ahmad, S., Adekunle, S. K., Maslehuddin, M., \& Azad, A. K. (2014). Properties of self-consolidating concrete made utilizing alternative mineral fillers. Construction and Building Materials, 68, 268-276.

https://doi.org/10.1016/j.conbuildmat.2014.06.096

Aslani, F., Ma, G., Yim Wan, D. L., \& Muselin, G. (2018). Development of high-performance self-compacting concrete using waste recycled concrete aggregates and rubber granules. Journal of Cleaner Production, 182, 553-566.

https://doi.org/10.1016/j.jclepro.2018.02.074

Assaad, J. J., \& Matar, P. (2018). Regression models to predict SCC pressure exerted on formworks containing vertical and transverse reinforcing bars. Materials and Structures, 51, 62. https://doi.org/10.1617/s11527-018-1188-x

Assaad, J. J., Matar, P., \& Gergess, A. (2020). Effect of quality of recycled aggregates on bond strength between concrete and embedded steel reinforcement. Journal of Sustainable CementBased Materials, 9(2), 94-111.

https://doi.org/10.1080/21650373.2019.1692315

Chen, T. Y. (2016). The influence of reinforced recycled coarse aggregates on the mechanical performance and durability of recycled concrete [Master Dissertation]. Harbin Institute of Technology.

China Academy of Building Research. (2012). Technical specification for application of self-compacting concrete (No. JGJ/T 283-2012).

China Academy of Building Research. (2010). Recycled coarse aggregate for concrete (No. GB/T 25177-2010).

China Academy of Building Research. (2016). Standard for testing method of performance on ordinary fresh concrete (No. GB/T 50080-2016).

Daczko, J. (2012). Self-consolidating concrete: Applying what we know. CRC Press. https://doi.org/10.1201/b11721

EFNARC. (2005). The European guidelines for self-compacting concrete, specification, production and use.

Ente Nazionale Italiano di Unificazione. (2013). Testing hardened concrete - Part 13: Determination of secant modulus of elasticity in compression (No. UNI EN 12390-13).

Etxeberria, M., Vázquez, E., \& Mari, A. (2006). Microstructure analysis of hardened recycled aggregate concrete. Magazine of Concrete Research, 58(10), 683-690.

https://doi.org/10.1680/macr.2006.58.10.683

Etxeberria, M., Vázquez, E., Marí, A., \& Barra, M. (2007). Influence of amount of recycled coarse aggregates and production process on properties of recycled aggregate concrete. Cement and Concrete Research, 37(5), 735-742.

https://doi.org/10.1016/j.cemconres.2007.02.002

Ferraris, C. F., Brower, L., Ozyildirim, C., \& Daczko, J. (2000). Workability of self-compacting concrete. In Proceedings of the PCI/FHWA/FIB International Symposium on High Performance Concrete (pp. 398-407). Orlando, Florida. Precast/ Prestressed Concrete Institute, Chicago, USA.

Ferreira, L. A., Brito, J. D., \& Barra, M. (2011). Influence of the pre-saturation of recycled coarse concrete aggregates on concrete properties. Magazine of Concrete Research, 63(8), 617627. https://doi.org/10.1680/macr.2011.63.8.617 
Gómez-Soberón, J. M. (2002). Porosity of recycled concrete with substitution of recycled concrete aggregate: An experimental study. Cement and Concrete Research, 32(8), 1301-1311. https://doi.org/10.1016/S0008-8846(02)00795-0

González-Fonteboa, B., \& Martínez-Abella, F. (2008). Concretes with aggregates from demolition waste and silica fume. Materials and mechanical properties. Building and Environment, 43(4), 429-437.

https://doi.org/10.1016/j.buildenv.2007.01.008

Guo, Z. H., Zhang, X. Q., Zhang, D. C., \& Wang, R. Q. (1982). Experimental investigation of the complete stress-strain curve of concrete. Journal of Building Structures, 3(1), 1-12. https://doi.org/10.14006/j.jzjgxb.1982.01.001

Hu, Q., Song, C., \& Zou, C. Y. (2009). Experimental research on the mechanical properties of recycled concrete. Journal of Harbin Institute of Technology, 41(4), 33-36.

Huang, J. (2012). The experiment of basic properties of recycled concrete from different sources [Master Dissertation]. Guangxi University.

Huang, Y. J., Sun, Y. D., Sun, H. S., \& Wang, Q. (2015). Theoretical analysis on mechanical behavior of axially loaded recycled aggregate concrete filled steel tubes. Mathematical Problems in Engineering, Article ID 270469. https://doi.org/10.1155/2015/270469

Khodair, Y., \& Bommareddy, B. (2017). Self-consolidating concrete using recycled concrete aggregate and high volume of fly ash, and slag. Construction and Building Materials, 153, 307-316. https://doi.org/10.1016/j.conbuildmat.2017.07.063

Kou, S. C., \& Poon, C. S. (2009). Properties of self-compacting concrete prepared with coarse and fine recycled aggregate. Cement and Concrete Composites, 31(9), 622-627. https://doi.org/10.1016/j.cemconcomp.2009.06.005

Kou, S. C., Poon, C. S., \& Chan, D. (2007). Influence of fly ash as cement replacement on the properties of recycled aggregate concrete. Journal of Materials in Civil Engineering, 19(9), 709-717. https://doi.org/10.1061/(ASCE)0899-1561(2007)19:9(709)

Li, W. G., Long, C., Tam, V. W. Y., Poon, C. S., \& Duan, W. H. (2017). Effects of nano-particles on failure process and microstructural properties of recycled aggregate concrete. Construction and Building Materials, 142, 42-50. https://doi.org/10.1016/j.conbuildmat.2017.03.051

Lin, J. (2007). Experiment research on compressive strength of recycled concrete and performance of recycled reinforced concrete beam [Master Dissertation]. Guangxi University.

Lotfi, S., Eggimann, M., Wagner, E., Mróz, R., \& Deja, J. (2015). Performance of recycled aggregate concrete based on a new concrete recycling technology. Construction and Building Materials, 95, 243-256.

https://doi.org/10.1016/j.conbuildmat.2015.07.021

Ma, J., Wang, Z. B., \& Wang, J. (2010). An experimental study on compressive strength of recycled aggregate concrete. Journal of Huaiyin Institute of Technology, 19(3), 54-58.

Matar, P., \& Assaad, J. J. (2019). Concurrent effects of recycled aggregates and polypropylene fibers on workability and key strength properties of self-consolidating concrete. Construction and Building Materials, 199, 492-500.

https://doi.org/10.1016/j.conbuildmat.2018.12.091

Matos, P. R. D., Foiato, M., \& Prudencio, L. R. (2019). Ecologi$\mathrm{cal}$, fresh state and long-term mechanical properties of highvolume fly ash high-performance self-compacting concrete. Construction and Building Materials, 203, 282-293. https://doi.org/10.1016/j.conbuildmat.2019.01.074
Mi, R. J, Pan, G. H., Liew, K. M., \& Kuang, T. (2020). Utilizing recycled aggregate concrete in sustainable construction for a required compressive strength ratio. Journal of Cleaner Production, 276, 124249.

https://doi.org/10.1016/j.jclepro.2020.124249

Noguchi, T., Park, W. J., \& Kitagaki, R. (2015). Risk evaluation for recycled aggregate according to deleterious impurity content considering deconstruction scenarios and production methods. Resources, Conservation and Recycling, 104, 405416. https://doi.org/10.1016/j.resconrec.2015.08.002

Okamura, H., \& Ouchi, M. (2003). Self-compacting concrete. Journal of Advanced Concrete Technology, 1(1), 5-15. https://doi.org/10.3151/jact.1.5

Olorunsogo, F. T., \& Padayachee, N. (2002). Performance of recycled aggregate concrete monitored by durability indexes. Cement and Concrete Research, 32(2), 179-185. https://doi.org/10.1016/S0008-8846(01)00653-6

Omrane, M., Kenai, S., Kadri, E. H., \& Aït-Mokhtar, A. (2017). Performance and durability of self compacting concrete using recycled concrete aggregates and natural pozzolan, Journal of Clean Production, 165, 415-430.

https://doi.org/10.1016/j.jclepro.2017.07.139

Ozawa, K. (1989). High-performance concrete based on the durability design of concrete structures [Conference presentation]. Proceedings of the 2nd East Asia-Pacific Conference on Structural Engineering and Construction.

Rahal, K. N. (2007). Mechanical properties of concrete with recycled coarse aggregate. Building and Environment, 42(1), 407-415. https://doi.org/10.1016/j.buildenv.2005.07.033

Safiuddin, Alengaram, U. J., Salam, A., Jumaat, M. Z., Jaafar, F. F., $\&$ Saad, H. B. (2011). Properties of high-workability concrete with recycled concrete aggregate. Materials Research, 14(2), 248-255. https://doi.org/10.1590/S1516-14392011005000039

Señas, L., Priano, C., \& Marfil, S. (2016). Influence of recycled aggregates on properties of self-consolidating concretes. Construction and Building Materials, 113, 498-505. https://doi.org/10.1016/j.conbuildmat.2016.03.079

Shi, Y. H., Wu, Z. J., Peng, P., \& Wang, D. F. (2012). Experimental study on comprehensive strength of recycled aggregate concrete. Industrial Construction, 42(4), 5-14. https://doi.org/10.13204/j.gyjz2012.04.003

Silva, R. V., de Brito, J., \& Dhir, R. K. (2018). Fresh-state performance of recycled aggregate concrete: A review. Construction and Building Materials, 178, 19-31.

https://doi.org/10.1016/j.conbuildmat.2018.05.149

Tam, V. W. Y., Gao, X. F., \& Tam, C. M. (2005). Microstructural analysis of recycled aggregate concrete produced from twostage mixing approach. Cement and Concrete Research, 35(6), 1195-1203. https://doi.org/10.1016/j.cemconres.2004.10.025

Tam, V. W. Y., \& Tam, C. M. (2007). Assessment of durability of recycled aggregate concrete produced by two-stage mixing approach. Journal of Materials Science, 42(10), 3592-3602. https://doi.org/10.1007/s10853-006-0379-y

Thomas, J., Thaickavil, N. N., \& Wilson, P. M. (2018). Strength and durability of concrete containing recycled concrete aggregates. Journal of Building Engineering, 19, 349-365. https://doi.org/10.1016/j.jobe.2018.05.007

Wang, Z. S. (2013). Study on mechanical properties and calculation of recycled aggregate concrete. Sichuan Building Science, 39(5), 238-242.

Wu, B., Liu, L., \& Zhao, X. L. (2016a). Test study on uniaxial compressive behaviors of compound concrete made of normal- 
strength demolished concrete lumps and high-strength selfcompacting concrete. Journal of Building Structures, 37(S2), 73-78. https://doi.org/10.1016/j.conbuildmat.2015.01.027

Wu, H., Duan, H., Zheng, L., Wang, J., Niu, Y., \& Zhang, G. (2016b). Demolition waste generation and recycling potentials in a rapidly developing flagship megacity of South China: Prospective scenarios and implications. Construction and Building Materials, 113, 1007-1016. https://doi.org/10.1016/j.conbuildmat.2016.03.130

Wu, S. H., Li, X. W., Xiao, H., \& Chai, Y. Y. (2009). Experimental research on deformation properties and stress-strain curve of C30 recycled concrete. Concrete, 12, 21-25. https://doi.org/10.3969/j.issn.1002-3550.2009.12.007

Xia, Q., Liu, B. K., \& Cao, Y. (2009). Experimental research on deformation behavior under uniaxial compression of recycled aggregate concrete. Journal of Anhui Institute of Architecture \& Industry (Natural Science), 17(1), 11-14.

Xiao, J. Z., Li, W. G., Fan, Y. H., \& Huang, X. (2012). An overview of study on recycled aggregate concrete in China (19962011). Construction and Building Materials, 31, 364-383. https://doi.org/10.1016/j.conbuildmat.2011.12.074

Xiao, X. (2008). Research on the basic strength features of recycled concrete. Shangdong University of Science and Technology.

Xing, F., Feng, N. Q., \& Ding, J. T. (1999). Recycled aggregate concrete. China Concrete and Cement Products, 2, 10-13. https://doi.org/10.19761/j.1000-4637.1999.02.003

Xing, Z. X., \& Zhou, Y. N. (1998). Study on the main performance of regenerated concrete. Journal of North China Institute of Water Conservancy and Hydroelectric Power, 19(2), 30-32. https://doi.org/10.19760/j.ncwu.zk.1998.02.008

Xu, J. J., Chen, Z. P., Yu, X. G., Chen, Y. L., \& Ye, P. H. (2012). Experimental study of elastic modulus and Poisson's ratios of long age recycled aggregate concrete. Concrete, 28(1), 15-17.

Yao, D. L., Chi, J. L., Yu, F., \& Zhang, Y. H. (2020). Influence of fly ash and recycled aggregate on self-compacting recycled aggregate concrete. Journal of Shenyang University of Technology, 42(2), 236-240.

Zhang, G. Q., Ning, J. X., Ni, S. N., Zheng, T., Zhong, L., Yi, Y. L., \& Chu, D. S. (2008). Experimental study of self-compacting concrete made with recycled aggregate. Concrete, 8, 59-75.

Zhang, L. L. (2009). Experimental investigation on material properties of recycled aggregate concrete [Master Dissertation]. Hefei University of Technology.

Zhang, X. G., Chen, Z. P., \& Xue, J. Y. (2015). Physical and mechanical performance of recycled aggregate concrete. Bulletin of the Chinese Ceramic Society, 34(6), 1684-1689.

https://doi.org/10.16552/j.cnki.issn1001-1625.2015.06.047 